\title{
Kronik Bel Ağrısı Olan ve Olmayan Öğretmenlerde Çalışma Postürü, Koşulları ve Yaşam Kalitesinin Karşılaştırılması
}

\author{
Comparison of working posture, conditions and quality of life in teachers with and without \\ chronic low back pain \\ Özge DEMIREL ${ }^{1}$, Şeyda TOPRAK ÇELENAY ${ }^{1}$ \\ ${ }_{1}^{1}$ Fzt., Ankara Yııdırım Beyazıt Üniversitesi, Sağlık Bilimleri Fakültesi, Fizyoterapi ve Rehabilitasyon Bölümü, Ankara, TÜRKIYE \\ ${ }^{2}$ Dr.Öğr.Üyesi, Ankara Yıldırım Beyazıt Üniversitesi, Sağıı Bilimleri Fakültesi, Fizyoterapi ve Rehabilitasyon Bölümü, Ankara, \\ TÜRKIYE
}

Öz

\begin{abstract}
Amaç: Kronik bel ağrısı olan ve olmayan öğretmenlerde çalışma postürünü, koşullarını ve yaşam kalitesini karşılaştırmaktı. Gereç ve Yöntem: Yüz elli üç öğretmen bel ağrısı grubu (n:80) ve kontrol grubu (n:73) olarak iki gruba ayrıldı. Ağrı Görsel Analog Skalası ile çalışma postürleri Hızlı Tüm Vücut Değerlendirmesi (HTVD) yöntemi ile ve yaşam kaliteleri Kısa Form-36 (KF-36) anketi ile değerlendirildi. Öğretmenlerin çalışma koşulları (meslekte deneyim süresi, danışmanı olunan öğrenci sayısı, çalışırken ki oturma süresi, ayakta durma süresi ve bilgisayar başında geçirilen süre, çalışma şekli ve çalıştığı okul seviyesi) sorgulandı. Sonuçlar: Bel ağrısı grubunda kontrol grubuna göre HTVD skorlarının arttığı ve zihinsel sağlık hariç yaşam kalitesi skorlarının azaldığı görüldü $(p<0,05)$. Bel ağrısı grubunda kontrol grubuna göre lisede çalışan öğretmen sayısı ve tam zamanlı olarak çalışma şekli daha fazlaydı $(p<0,05)$. Gruplar arasında mesleki deneyim süresi, danışman olunan öğrenci sayısı, çalışmadaki günlük oturma, ayakta durma ve bilgisayar kullanım süreleri arasında fark yoktu $(p>0,05)$. Tartışma: Bel ağrısı olan öğretmenlerde çalışma postürünün ve yaşam kalitelerinin daha kötü olduğu , lisede çalışan öğretmen sayısı ve tam zamanlı olarak çalışma şeklinin daha fazla olduğu ve yaşam kalitelerinin azaldığı görüldü. Öğretmenlerde bu konu ile ilgili farkındalığın oluşturulması sağlığının korunması ve iş veriminin artırılması açısından önemli olabilir.
\end{abstract}

Anahtar kelimeler: Bel ağrısı; postür; yaşam kalitesi

\section{ABSTRACT}

Purpose: To compare working posture, conditions and quality of life in teachers with and with out chronic low back pain. Material and Methods: One hundred and fifty-three teachers were divided into two groups as the group with low back pain $(n: 80)$ and the control group (n:73). Pain was assessed by Visual Analogue Scale, the working postures were assessed by Rapid Entire Body Assessment (REBA) and the quality of life, by Short Form-36. The working conditions of the teachers (professional experience period, number of advisor students, daily sitting duration, standing duration and computer usage times while working, working style and school level) were questioned. Results: It was seen that the REBA scores were higher and the quality of life scores except mental health were lower in the low back pain group compared to the control group $(p<0.05)$. In the low back pain group, the number of teachers working in high school and full-time working style were higher than control group $(p<0.05)$. There was no difference between groups in terms of professional experience period, number of advisor students, daily sitting duration, standing duration and computer usage times while working $(p>0.05)$. Conclusion: It was seen in the teachers with low back pain that working posture and the quality of life were worse, the number of teachers working in high school and full-time working style were more. Creating awareness about this issue in teachers may be important in terms of protecting health and increasing work efficiency.

Keywords: Low back pain; posture; quality of life

Sorumlu Yazar (Corresponding Author): Özge DEMIREL E-mail: ozgefzt@gmail.com 
Bel ağrısı; 12. kosta ile alt gluteal katlantılar arasındaki bölgede yer alan anatomik yapılardan kaynaklanan ağrı olarak tanımlanır (Balagué, Mannion ve Pellisé, 2012). Bel ağrısı yaşayan olguların büyük bir kısmında (yaklaşık \%90) bel ağrısının özel bir nedeni yokken, spesifik nedenler olguların ancak \%5-10'luk kısmında görülmektedir (Krismer ve Van Tulder, 2007). Prevalans tahminleri, kullanılan bel ağrısı tanımına göre değişebilmektedir. Yaşam boyu bel ağrısı prevalansının \%84 gibi yüksek olabileceği bildirilmiştir (Balagué ve ark, 2012). Kadınlarda bel ağrısı gelişme riski erkeklere göre 2 kat daha fazladır (Jiménez-Sánchez, Fernández-de-las-Peñas ve Carrasco-Garrido, 2012). Non-spesifik bel ağrısı dünya çapında önemli bir halk sağlığı sorunu haline gelmekte, iş gücü kayıplarına ve toplumlarda ciddi ekonomik yüklere neden olmaktadır (Van Tulder, Koes ve Bombardier, 2002; Hoy , Brooks ve Blyth,2010).

Bel ağrısında, nosiseptif uyarıların varlığı, kas fonksiyonunda azalmaya bağlı gelişen kassal inhibisyon ve atrofi, konnektif dokunun yapısındaki değişmeler, emosyonel stres varlığı, torakolumbar, nöronal inflamasyon ve bası patofizyolojik olarak ortaya konan mekanizmalardır (Langevin ve Sherman, 2007; Bednar, Orr ve Simon, 1995; Valkenburg ve Haanen, 1982). Bel ağrısının gelişimini ve süresini; yaş, cinsiyet, genetik faktörler, psikososyal faktörler, sigara, gebelik ve mesleki durum gibi birçok risk faktörü etkileyebilmektedir (Klineberg, Mazanec ve Orr, 2007).

Mesleki olarak maruz kalınan, tekrarlayıcı hareket ve zorlanmalar, birikimli travmalar, uygun olmayan çalışma postürü, psikososyal faktörler ve ergonomik yetersizlikler bel ağrısı gelişimini tetikleyebilmektedir (Bilir, 2007; Ayanoğlu, 2007). Öğretmenler, birçok farklı meslek grubunda (ofis çalışanları, diş hekimleri, sağlık çalışanları vb) olduğu gibi çalışma koşulları nedeniyle bel ağrısı gelişimi açısından yüksek riske sahiptir (Cardoso, De Queiroz Batista Ribeiro ve Maria de Araújo, 2009). Çalışma postürü de klinikte mesleksel olarak önem taşımaktadır (Bilir, 2007) . Günümüzde çalışma postürünü değerlendiren birçok yöntem bulunmaktadır (David, 2005). Postüral analiz yöntemleri kullanım ve duyarlılık açısından farklı sonuçlar verebilmektedir. Çalışma postürlerini analiz etmek ve diğer yöntemlerdeki kısıtlılıkları ortadan kaldırmak için geliştirilen Hızlı Tüm Vücut Değerlendirilme (HTVD) yöntemi, pratik, kısa sürede tamamlanabilen, tüm vücudun değerlendirilmesine olanak sağlayan, tüm işyerlerinde kullanılabilecek detaylı ve duyarlı bir analiz imkanı sağlamaktadır
(Hignett ve McAtamney, 2000). Literatürde, farklı meslek kollarında (ofis çalışanları, gıda endüstrisi, inşaat, sanayi tarzı iş yerleri, sağlık çalışanları vb) çalışma postürlerinin HTVD yöntemiyle değerlendirildiği çalışmalar mevcuttur (Dima ve Awwad, 2016; Pillastrini, 2007; Joseph ve Imbeau, 2011; Shanahan, Vi ve Salas, 2013; Kee ve Karwowski, 2007; Chiasson, Imbeau ve Aubry, 2012; Janowitz, Gillen ve Ryan, 2006; Jones ve Kumar, 2010; Gentzler ve Stader, 2010).Literatürde öğretmenlerin çalışma postürünü HTVD yöntemiyle değerlendiren bir çalışmaya rastlanmamıştır.

Ağrı, yaşam kalitesini olumsuz etkileyen semptomlardan birisidir (Katz, 2002). Öğretmenlerde bel ağrısı günlük yaşam aktivitelerinde fonksiyonel kısıtlılık ve psikosoyal yönden olumsuz etkiler oluşturarak yaşam kalitesini kötü yönde etkilemektedir (Durmus ve Ilhanlı, 2012). Çalışmalarda bel ağrısı olan öğretmenlerin ağrı şikayeti olmayan öğretmenlere göre yaşam kalitelerinin olumsuz etkilenebileceği ifade edilmiştir (Durmus ve Ilhanlı, 2012; Karakaya, Karakaya ve Tunc, 2015).

Böylece, çalışmamızda kronik bel ağrısı olan ve olmayan öğretmenlerde çalışma postürünün, çalışma koşullarının ve yaşam kalitesinin karşılaştırılması amaçlandı. $\mathrm{Bu}$ amaçlar doğrultusunda hipotezlerimiz: H0: Kronik bel ağrısı olan öğretmenlerde bel ağrısı olmayanlara göre çalışma postürü benzerdir. H1: Kronik bel ağrısı olan öğretmenlerde bel ağrısı olmayanlara göre çalışma postürü farklıdır.

\section{GEREÇ VE YÖNTEM}

Çalışma Dizaynı

Bu çalışmada vaka kontrol çalışma dizaynı kullanıldı. Çalışmamız, Ankara Yıldırım Beyazıt Üniversitesi Etik Kurul'u tarafından onaylandı (Onay numarası: 68/01) ve Ankara İ Milli Eğitim Müdürlüğü'nden gerekli izinler alındı. Çalışmamız Ankara'nın Mamak ilçesindeki okullarda 01.03.2018-30.05.2018 tarihleri arasında gerçekleştirildi.

\section{Katılımcılar}

Çalışmamızda, Ankara'nın Mamak ilçesindeki okullarda çalışan; ilkokul, ortaokul ve lisede çalışan farklı branşlardaki toplam 190 öğretmen değerlendirildi. Çalışmaya katılmaya gönüllü olan, en az iki yıllık çalışma deneyimine sahip, mekanik nedenler veya disk herniasyonu olan tanısı hekim tarafından konulmuş kronik (>12 hafta süren) bel ağrısı olan ve olmayanlar ile 25-60 yaş arası öğretmenler çalışmaya dahil edildi. Doğuştan veya 
sonradan kazanılan spinal deformitesi olan, alt ekstremite deformitesi olan (dekontraktür, kısalık), önceden omurga cerrahisi geçirmiş, malignitesi olan, bel bölgesini etkileyen her türlü travma, kırık, tümoral, inflamatuar ve enfeksiyöz bir duruma sahip olan, gebe olan, nörolojik ve romatolojik hastalığı olan öğretmenler çalışma dışında tutuldu.

Ön çalışma için bel ağrısı olan ve olmayan öğretmenlerden rastgele 10' ar birey alındı. Çalışma için gerekli örneklem büyüklüğünü belirleyebilmek amacı ile G*Power (G*Power Ver. 3.0.10, Franz Faul, Universität Kiel, Germany) paket programı kullanıldı. HTVD'ye göre çalışmaya $d=0,49$ etki genişliği, $\alpha=0,05$ tip I hata, $\beta=0,10$ tip II hata ile $\% 90$ güç elde edebilmek için en az 146 olgudan (her grup için 73'er olgu) oluşan bir örneklem alınmasına gerek olduğu hesaplandı. Öğretmenler bel ağrısı şikayeti durumuna göre bel ağrısı olan grup ve bel ağrısı olmayan kontrol grubu olarak 2 gruba ayrıldı. Çalışmanın amacı ve içeriği öğretmenlere anlatıldı. Çalışmaya katılmak isteyen öğretmenlerden yazılı bilgilendirilmiş onam formu alındı.

\section{Değerlendirmeler}

Çalışmaya katılan öğretmenlerin fiziksel ve demografik özellikleri (yaş, cinsiyet, boy uzunluğu, vücut ağırığı) kaydedildi. Vücut kütle indeksi (VKi), vücut ağırlığının boy uzunluğunun karesine bölünmesi ile hesaplandı. Ağrı şiddeti güvenilirliği Clark ve arkadaşları tarafından yapılmış olan Görsel
Analog Skalası (GAS) ile değerlendirildi (Clark, Lavielle ve Martinez, 2003). Bu skalada, 10 cm'lik bir çizgiden oluşmakta olup "0"ağrının olmadığını, "10" ise dayanılmaz ağrıyı ifade etmektedir. Bel ağrısı olan öğretmenlerden ağrı şiddetlerini bu çizgi üzerine işaretlemeleri istendi ve öğretmenlerin ağrı şiddetleri başlangıç noktası ile işaretlenen nokta arası cetvelle ölçülerek cm cinsinden hesaplandı.

Öğretmenlerde çalışma postürü HTVD yöntemi kullanılarak değerlendirildi. HTVD, çok sık tekrarlanan hareketler, en uzun süre boyunca çalışılan postür, sık kullanılan, zorlayıcı ve stabil olmayan postürler gibi birçok postürün analizine imkan sağlamaktadır (Stanton, 2005). Çalışmamızda, çalışma süresince en sık maruz kalınan postürler uzun süreli oturma, tahtaya yazı yazma, ayakta durma ve ödev kontrolü olarak öğretmenler tarafından belirtildi, her bir öğretmen için en sık kullandıkları postür değerlendirmeye alındı. Çalışma postürleri, fotoğraf yardımıyla HTVD sisteminde analiz edildi. Gövde, boyun ve bacak postürlerinin açısal skorları tablo A'ye yerleştirildiğinde buradan elde edilen skora yük/kuvvet skorunun eklenmesiyle A skoru; kol, ön kol ve bilek postürlerinin açısal skorları tablo B'ye yerleştirildiğinde buradan elde edilen skora kavrama skorunun eklenmesiyle B skoru elde edildi. Tablo C'ye göre A ve B skorları birleştirilerek C skoru, C skoruna aktivite skorunun eklenmesiyle HTVD skoruna ulaşıldı.

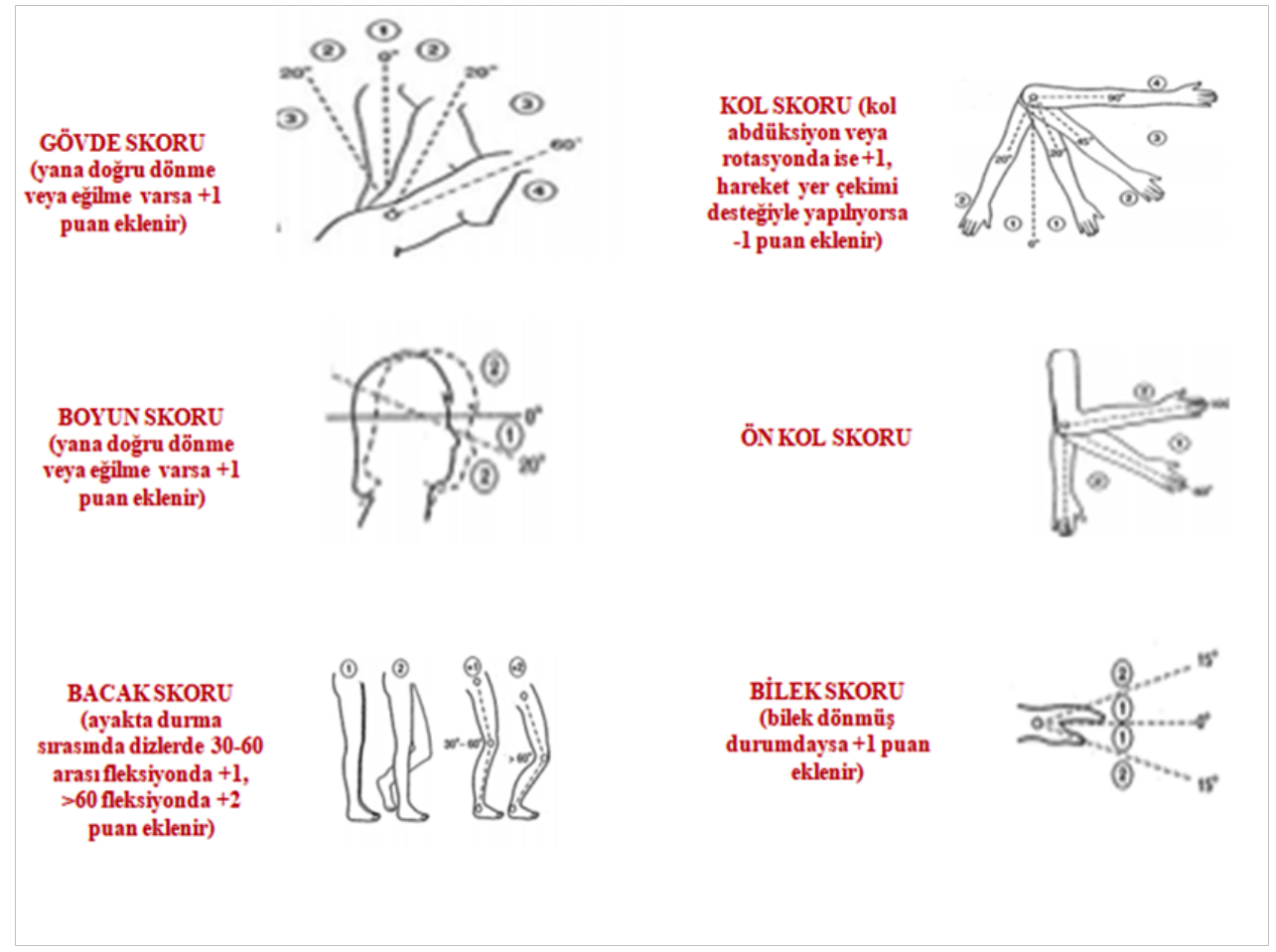

Şekil 1. Skorların açısal olarak hesaplanması. 


\begin{tabular}{|c|c|c|c|c|c|c|c|c|c|c|c|c|c|}
\hline \multirow{4}{*}{ TABLOA } & & \multicolumn{12}{|c|}{ BOYUN } \\
\hline & & \multirow{2}{*}{\multicolumn{4}{|c|}{1}} & \multicolumn{4}{|c|}{2} & \multicolumn{4}{|c|}{3} \\
\hline & & & & & & \multicolumn{4}{|c|}{ BACAKIAR } & \multicolumn{4}{|c|}{ BACAKIAR } \\
\hline & & 1 & 2 & 3 & 4 & 1 & 2 & 3 & 4 & 1 & 2 & 3 & 4 \\
\hline \multirow{5}{*}{ GÖVDE } & 1 & 1 & $\overline{2}$ & 3 & 4 & 1 & 2 & 3 & 4 & 3 & $\overline{3}$ & 5 & 6 \\
\hline & 2 & 2 & 3 & 4 & 5 & 3 & 4 & 5 & 6 & 4 & 5 & 6 & 7 \\
\hline & 3 & 2 & 4 & 5 & 6 & 4 & 5 & 6 & 7 & 5 & 6 & 7 & 8 \\
\hline & 4 & 3 & 5 & 6 & 7 & 5 & 6 & 7 & 8 & 6 & 7 & 8 & 9 \\
\hline & 5 & 4 & 6 & 7 & 8 & 6 & 7 & 8 & 9 & 7 & 8 & 9 & 9 \\
\hline
\end{tabular}

\begin{tabular}{|l|l|l|l|}
\hline \multicolumn{5}{|c|}{ YUK/KUVTET SKORU } \\
\hline 1 & 2 & 3 & +1 \\
\hline$<5 \mathrm{~kg}$ & $5-10 \mathrm{~kg}$ & $>10 \mathrm{~kg}$ & $\begin{array}{l}\text { Ani veya hızlı kuvvet } \\
\text { artıș }\end{array}$ \\
\hline
\end{tabular}

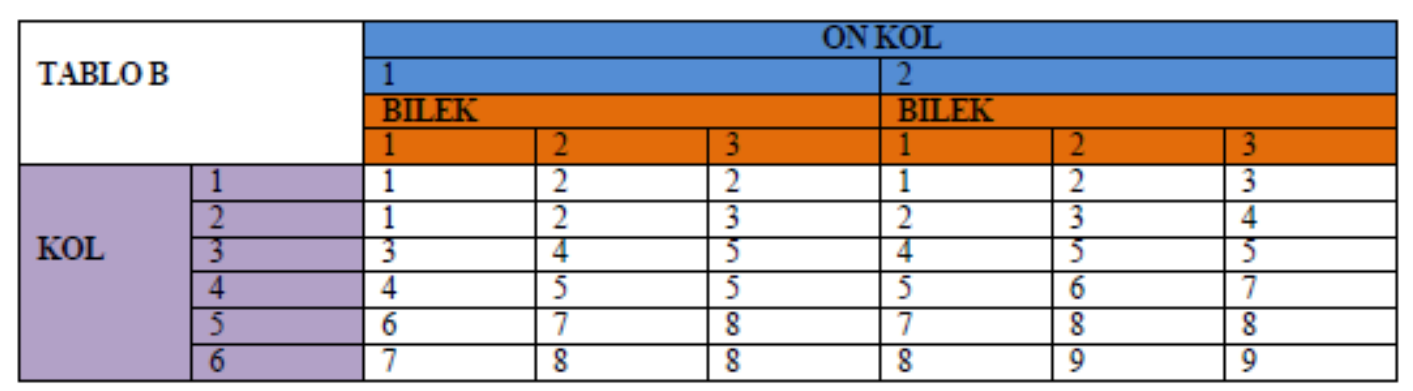

\begin{tabular}{|l|l|l|l|}
\hline \multicolumn{5}{|c|}{ KAVRAMA SKORU } \\
\hline 0 (iyi) & 1 (uygun) & 2 (kötii) & (uygun değil) \\
\hline $\begin{array}{l}\text { Iyi bir tutma kolu ve orta } \\
\text { şiddette kavrama gücü }\end{array}$ & $\begin{array}{l}\text { El tutuşu uygun ama ideal } \\
\text { değil veya vücudun başka } \\
\text { bir bölgesi ile kavrama } \\
\text { uygun }\end{array}$ & $\begin{array}{l}\text { El tutuşu uygun } \\
\text { olmamasma rağmen } \\
\text { mümkīn }\end{array}$ & $\begin{array}{l}\text { Zor ve güvenli olmayan } \\
\text { tutuş, tutma kolu yok, } \\
\text { vücudun başka bir } \\
\text { bölgesi kullamlarak tutuş } \\
\text { uygun değil }\end{array}$ \\
\hline
\end{tabular}

\begin{tabular}{|c|c|c|c|c|c|c|c|c|c|c|c|c|c|}
\hline \multirow{2}{*}{$\begin{array}{l}\text { TABLO } \\
\mathrm{C}\end{array}$} & & \multicolumn{12}{|c|}{ B SKORU } \\
\hline & & 1 & 2 & 3 & 4 & 5 & 6 & 7 & 8 & 9 & 10 & 11 & 12 \\
\hline \multirow{12}{*}{$\begin{array}{l}\text { A } \\
\text { SKORU }\end{array}$} & 1 & 1 & 1 & 1 & 2 & 3 & 3 & 4 & 5 & 6 & 7 & 7 & 7 \\
\hline & 2 & 1 & 2 & 2 & 3 & 4 & 4 & 5 & 6 & 6 & 7 & 7 & 8 \\
\hline & 3 & 2 & 3 & 3 & 3 & 4 & 5 & 6 & 7 & 7 & 8 & 8 & 8 \\
\hline & 4 & 3 & 4 & 4 & 4 & 5 & 6 & 7 & 8 & 8 & 9 & 9 & 9 \\
\hline & 5 & 4 & 4 & 4 & 5 & 6 & 7 & 8 & 8 & 9 & 9 & 9 & 9 \\
\hline & 6 & 6 & 6 & 6 & 7 & 8 & 8 & 9 & 9 & 10 & 10 & 10 & 10 \\
\hline & 7 & 7 & 7 & 7 & 8 & 9 & 9 & 9 & 10 & 10 & 11 & 11 & 11 \\
\hline & 8 & 8 & 8 & 8 & 9 & 10 & 10 & 10 & 10 & 10 & 11 & 11 & 11 \\
\hline & 9 & 9 & 9 & 9 & 10 & 10 & 10 & 11 & 11 & 11 & 12 & 12 & 12 \\
\hline & 10 & 10 & 10 & 10 & 11 & 11 & 11 & 11 & 12 & 12 & 12 & 12 & 12 \\
\hline & 11 & 11 & 11 & 11 & 11 & 12 & 12 & 12 & 12 & 12 & 12 & 12 & 12 \\
\hline & 12 & 12 & 12 & 12 & 12 & 12 & 12 & 12 & 12 & 12 & 12 & 12 & \\
\hline
\end{tabular}

\begin{tabular}{|l|l|l|}
\hline \multicolumn{3}{|c|}{ AKTIVTIE SKORU (+1) } \\
\hline $\begin{array}{l}\text { Bir veya daha fazla vïcut } \\
\text { bölgesi sabitse (ömeğin } \\
>1 \text { dakijka) }\end{array}$ & $\begin{array}{l}\text { Kısa aralıklarla tekrar eden işler (ömeğin 1 dakikada } \\
\text { 4'ten fazla tekrar eden iş) }\end{array}$ & $\begin{array}{l}\text { Hareket hızlı veya büyük } \\
\text { değişikliklere yol } \\
\text { açıyorsa }\end{array}$ \\
\hline
\end{tabular}

Şekil 2. HTVD skorunun belirlenmesi. 
HTVD skoru, literatür kullanılarak her biri risk seviyesi ve aktivite gerekliliği açısından farklı anlam ifade eden 5 kategoriye (kategori 0-4) ayrılmaktadır. HTVD skoru 1 ile 15 arasında bir değer alabilmekte, skor yükseldikçe çalışma postürünün kötü olduğunu göstermekte ve böylece kas iskelet sistemi problemleri gelişme risk seviyesi ve aktivite gerekliliği artış ile ilgili bilgi vermektedir (Hignett ve ark, 2000; Dima ve ark, 2016; Stanton, 2005). HTVD skoru 1 puan kategori 0- inmal edilebilir risk düzeyini, skor 23 kategori 1- düşük risk düzeyini, skor 4-7 kategori 2orta risk düzeyini, skor 8-10 kategori 3-yüksek risk düzeyini ve skor 11-15 kategori 4-çok yüksek risk düzeyini ifade etmektedir. Kategori 0'da risk seviyesi inmal edilebilir düzeyde ve aktivite gerekmeyebilirken, kategori 4'e doğru risk seviyesi ve aktivite gerekliliği artmaktadır .

Tablo 1. HTVD skoruna göre risk düzeyleri.

\begin{tabular}{llll}
\hline Kategori & HTVD Skoru & Risk Seviyesi & Aktiviteler \\
\hline $\mathbf{0}$ & 1 & İhmal edilebilir & Aktivite Önerilmeyebilir \\
\hline $\mathbf{1}$ & $2-3$ & Düşük & Aktivite Önerilebilir. \\
\hline $\mathbf{2}$ & $4-7$ & Orta & Gerekli \\
\hline $\mathbf{3}$ & $8-10$ & Yüksek & Kısa zaman içinde gerekli \\
\hline $\mathbf{4}$ & $11-15$ & Çok yüksek & Hemen gerekli \\
\hline
\end{tabular}

Ayrıca öğretmenlerin çalışma koşulları (meslekte deneyim süresi (yıl), ortalama danışmanı olunan öğrenci sayısı, çalışırken ki ortalama oturma süresi (dakika), çalışırken ki ortalama ayakta durma süresi (saat), bilgisayar başında geçirilen ortalama çalışma süresi (dakika), çalışma şekli (yarı zamanlı ve tam zamanlı) ve çalıştığı okul seviyesi (ilkokul, ortaokul, lise)) ve branşları kaydedildi.

Çalışmaya katılan tüm öğretmenlerin yaşam kalitesi Kısa Form-36 (KF-36) anket formu kullanılarak değerlendirildi. KF-36, Türkçe geçerlik ve güvenilirliği gösterilmiş, sağlığın 8 alt parametresini 36 soru ile tarayan, sık kullanılan bir yaşam kalitesi anketidir (Kocyigit, Aydemir ve Fisek, 1999). Değerlendirmede, fiziksel fonksiyon, fiziksel rol kısıtııı̆ı, duygusal rol kısıtılığı, enerji, zihinsel sağlık, sosyal fonksiyon, bedensel ağrı ve genel sağlık algısı parametreleri "0" ile "100" arasında bir değer almakta, değerin düşük olması kötü sağlık durumunu yansıtmaktadır (Kocyigit ve ark, 1999).

\section{İstatistiksel Analiz}

Değişkenlerin normal dağılıma uygunluğu görsel (histogram ve olasılık grafikleri) ve analitik yöntemlerle (Kolmogorov-Smirnov testi) incelendi. Tanımlayıcı analizler normal dağılan değişkenler için ortalama (X) ve standart sapma (SS), normal dağılmayan değişkenler için ortanca ve çeyrekler arası genişlik (ÇAG), kategorik değişkenler için sayı (\%) verildi. Gruplar arasında; yaş, boy, vücut ağırlığı ve VKI skorları normal dağılım gösterdiğinden bağımsız gruplarda t testi ile, çalışma süresi (yıl), oturarak çalışma süresi (dk), ayakta çalışma süresi (saat), bilgisayar başında çalışma süresi (dk), danışmanı olunan öğrenci sayısı, HTVD skoru ve KF-36 skoru normal dağılım göstermediği için MannWhitney $U$ testi ile ve okul seviyesi, çalışma şekli ve cinsiyet parametreleride kategorik değişkenler olduğu için Chi-square testi ile karşılaştırıldı. İstatistiksel analizler ve hesaplamalar için IBM SPSS Statistics 21.0 (IBM Corp. Released 2012. IBM SPSS Statisticsfor Windows, Version 21.0. Armonk, NY: IBM Corp.) kullanıldı. İstatistiksel anlamlılık düzeyi $p<0,05$ olarak kabul edildi.

\section{SONUÇLAR}

Bu çalışma için toplam 190 öğretmen ile görüşüldü. Dahil edilme ve çıkartılma kriterlerine göre çalışmamıza 153 öğretmen alındı. Çalışmaya dahil edilen öğretmenlerde, bel ağrısı olan $(n=80$, yaş: $42,50 \pm 8,58$ yıl, VKi: $26,13 \pm 3,58 \mathrm{~kg} / \mathrm{m} 2$ ) ve olmayan ( $n=73$, yaş: 40,16 $\pm 7,97 \mathrm{yıl}$, VKi: $25,10 \pm 3,2 \mathrm{~kg} / \mathrm{m} 2$ ) grupta fiziksel ve demografik özellikler benzerdi (pyaş: 0,084, pvki: 0,064). Çalışmaya katılan bel ağrısı olan öğretmenlerin \%66,2'sinin kadın, \%33,8'inin erkek, bel ağrısı olmayan öğretmenlerin ise \%52,1'inin kadın, \%47,1'inin erkeklerden oluştuğu görüldü. Gruplar arasında cinsiyet yönünden fark olmadığı bulundu (p:0,099). Çalışmamızda bel ağrısı olan öğretmenlerin ağrı şiddeti ortalamasının $5,41 \pm 1,43 \mathrm{~cm}$ ve ağrı şiddetinin orta düzeyde olduğu tespit edildi. 


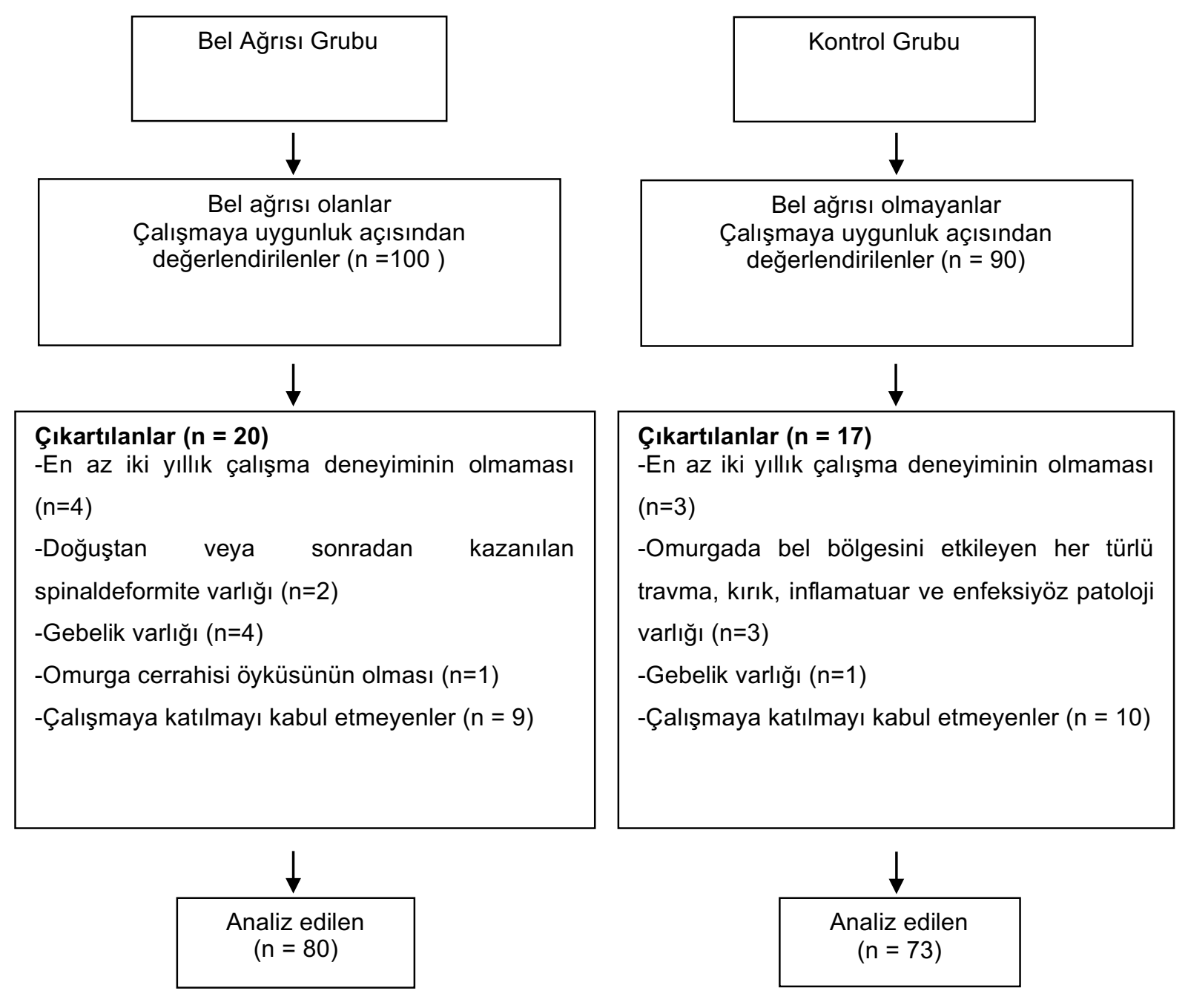

Şekil 3. Katılımcılar için akış şeması.

Gruplar arasında HTVD skorları karşılaştırıldığında; bel ağrısı olan öğretmenlerde bel ağrısı olmayan öğretmenlere göre skorun anlamlı olarak daha yüksek olduğu görüldü ( $p: 0,001$ ) ve HTVD skoruna göre bel ağrısı olan grupta genel kas iskelet sistemi problemleri gelişme düzeyi orta ve yüksek iken, bel ağrısı olmayan öğretmenlerde genel kas iskelet sistemi problemleri gelişme düzeyi düşük ve orta düzeyde olduğu görüldü.

Tablo 2. Grupların Çalışma Postürünün ve Çalışma Koşullarının Karşılaştırılması.

\begin{tabular}{lcccc}
\hline & Bel Ağrısı Grubu & Kontrol Grubu & \\
\hline ÇalışmaPostürü ve Koşulları & $\begin{array}{c}\text { Ortanca(ÇAG) } \\
(\mathbf{n = 8 0 )}\end{array}$ & $\begin{array}{c}\text { Ortanca(ÇAG) } \\
(\mathbf{n = 7 3 )}\end{array}$ & $\mathbf{Z}$ & $\mathbf{p}$ \\
\hline Çalışma Postürü (HTVD skoru) & $6,0(2,0)$ & $5,0(2,0)$ & $-3,289$ & $0,001^{a *}$ \\
Çalışma Yılı (yı) & $19,0(11,0)$ & $17,0(12,50)$ & $-1,496$ & $0,135^{\mathrm{a}}$ \\
Danışmanı OlunanÖğrenci Sayısı & $100,0(115,0)$ & $100,0(184,0)$ & $-0,900$ & $0,368^{a}$ \\
Çalışırken ki Oturma Süresi (dk) & $60,0(90,0)$ & $60,0(87,50)$ & $-0,167$ & $0,867^{\mathrm{a}}$ \\
Çalışırken ki Ayakta Durma Süresi (sa) & $6,0(2,0)$ & $6,0(2,25)$ & $-1,355$ & $0,175^{\mathrm{a}}$ \\
Günlük Bilgisayar Başında Çalışma Süresi (dk) & $60,0(75,0)$ & $60,0(115,0)$ & $-0,867$ & $0,386^{\mathrm{a}}$ \\
\hline
\end{tabular}

${ }^{*} \mathrm{p}<0,05$, HTVD: Hızlı Tüm Vücut Değerlendirme; ÇAG:Çeyrekler Arası Genişlik; dk:dakika; sa:saat; ' ${ }^{a}$ : MannWhitney U testi; X: Ortalama; SS: Standart sapma; VKi: Vücut kütle indeksi 
Bel ağrısı olan öğretmenlerin \%17,5'i ilkokulda, \%26,3'ü ortaokulda, \%56,3'ü lisede çalışmakta iken, bel ağrısı olmayan öğretmenlerin \%20,5'i ilkokulda, \%64,4'ü ortaokulda ve \%15,1'i lisede çalışmaktaydı. Bel ağrısı olan öğretmenlerin \%43,8'i yarı zamanlı, $\% 56,3$ 'ü tam zamanlı çalışma şekline, bel ağrısı olmayan öğretmenlerin \%84,9'u yarı zamanlı, \%15,1'i tam zamanlı çalışma şekline sahipti. Bel ağrısı olan öğretmenlerde bel ağrısı olmayan öğretmenlere göre lisede çalışan öğretmen sayısı ve tam zamanlı olarak çalışma şekli anlamlı olarak daha fazla bulundu $(p<0,0001)$. Grupların çalışma yılı (p:0,135), danışman olunan öğrenci sayısı ( $p: 0,368)$, çalışmadaki günlük oturma süresi ( $p: 0,867)$, ayakta kalma süresi ( $p: 0,175)$ ve bilgisayar kullanım süresi ( $p: 0,386)$ arasında anlamlı bir fark bulunmadı. Çalışmamızda bel ağrısı grubundaki öğretmenlerinin çoğu sınıf öğretmenlerinden oluşmaktaydı $(\% 21,3)$.

Çalışmamızda bel ağrısı grubundaki öğretmenlerde kontrol grubundaki öğretmenlere göre yaşam kalitesinin fiziksel fonksiyon ( $p: 0,010)$, fiziksel rol kısıtlılığı ( $p: 0,001)$, duyusal rol kısıtlılığı $(p<0,001)$, enerji $(p<0,001)$, sosyal fonksiyon ( $p: 0,028)$, bedensel ağrı $(p<0,001)$ ve genel sağlık algısı $(p<0,001)$ skorlarında anlamlı bir azalma olduğu görüldü. Ancak gruplar arasında zihinsel sağlık durumlarında fark olmadığı belirlendi (p:0,251).

Tablo 3. Grupların Yaşam Kalitesi Skorlarının Karşılaştırılması.

\begin{tabular}{|c|c|c|c|c|}
\hline & Bel Ağrısı Grubu & Kontrol Grubu & & \\
\hline $\begin{array}{l}\text { Yaşam Kalitesi } \\
\text { (KF-36) }\end{array}$ & $\begin{array}{c}\text { Ortanca (ÇAG) } \\
(n=80)\end{array}$ & $\begin{array}{c}\text { Ortanca (ÇAG) } \\
(n=73)\end{array}$ & $\mathbf{Z}$ & $\mathbf{p}$ \\
\hline Fiziksel Fonksiyon & $60,0(20,0)$ & $75,0(50,0)$ & $-2,567$ & $0,010^{\mathrm{a}^{*}}$ \\
\hline Fiziksel Rol Kısıtlılığı & $50,0(75,0)$ & $95,0(47,50)$ & $-3,393$ & $0,001^{a^{*}}$ \\
\hline Duyusal Rol Kısıtlılığı & $66,66(33,33)$ & $75,0(66,67)$ & $-3,662$ & $<0,001^{a^{\star}}$ \\
\hline Enerji & $50,0(20,0)$ & $66,66(55,0)$ & $-4,360$ & $<0,001^{a^{*}}$ \\
\hline Zihinsel Sağlık & $60,0(28,0)$ & $64,0(25,0)$ & $-1,147$ & $0,251^{a}$ \\
\hline Sosyal Fonksiyon & $62,50(25,0)$ & $72,0(25,75)$ & $-2,192$ & $0,028^{a^{*}}$ \\
\hline Bedensel Ağrı & $45,0(24,38)$ & $77,50(27,50)$ & $-5,022$ & $<0,001^{a^{*}}$ \\
\hline Genel Sağlık Algısı & $45,0(25,0)$ & $77,50(45,0)$ & $-6,315$ & $<0,001^{a^{*}}$ \\
\hline
\end{tabular}

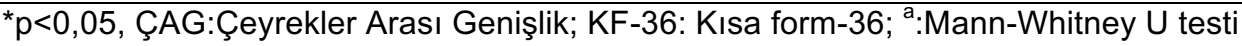

\section{TARTIŞMA}

$\mathrm{Bu}$ çalışma, bel ağrısı olan ve olmayan öğretmenlerde çalışma postürünün ,koşullarının ve yaşam kalitesinin karşılaştırılması amacıyla gerçekleştirildi. Çalışmamızda, bel ağrısı olan öğretmenlerde bel ağrısı olmayan öğretmenlere göre çalışma postürünün daha kötü olduğu, lise okul seviyesinin ve tam zamanlı olarak çalışma şeklinin daha fazla olduğu ve yaşam kalitesinin fiziksel fonksiyon, fiziksel rol kısıtılığı, duyusal rol kısıtlılığı, enerji, sosyal fonksiyon, bedensel ağrı ve genel sağlık algısı parametrelerinde anlamlı bir azalma olduğu bulundu.

Kötü çalışma postürü, farklı meslek kollarında olduğu gibi öğretmenler için de kas iskelet sistemi problemleri gelişimi açısından önemli bir tetikleyici faktördür (Dima ve ark, 2016). Çalışma postürlerinin analizi, gerekli ergonomik düzenlemelerin yapılması ve koruyucu önlemlerin alınması açısından önem arz etmektedir (Dima ve ark, 2016). Tüm vücut postürünün pratik ve detaylı bir şekilde analizini sağlayan HTVD yöntemi, bugüne kadar laboratuvar çalışanları (Atasoy, 2010), üniversite öğrencileri (De Sa ve Nascimento, 2006) ve atölye çalışanları (Hashim, Dawal ve Yusoff, 2012) gibi farklı meslek kollarında kas iskelet sistemi problemleri gelişme riskinin değerlendirilmesinde kullanılmış ve ergonomik düzenlemelerle iş veriminin artırılması ile ilgili literatüre bilgi sunulmuştur. Ülkemizde yapılan bir çalışmada öğretmenlerde çalışma postürleri Owako Çalışma Postür Analiz Sistemi (OÇPAS) kullanılarak değerlendirilmiş ve çalışma sonucunda öğretmenlerin çalışma postürü risk seviyesi \%58'inde kategori 1 (normal postür, ergonomik düzenleme gerektirmez), \% 30,7'sinde kategori 2 
(fazla stres altında olmayan postür, yakın gelecekte ergonomik düzenleme gerektirebilir), \% 10,2'sinde kategori 3 (fazla yüklenme ve stres, mümkün olan en kısa zamanda ergonomik düzenleme gerektirir), \% 1,1'inde kategori 4 (çok fazla yüklenme ve stres, acil ergonomik düzenleme gerektirir) olarak bulunmuştur (Apaydın, Erol ve Kocyigit, 2016). Burada kullanılan OÇPAS sistemi gözleme dayalıdır ve açısal değerlendirme yapılamamaktadır. HTVD yönteminin, pratik olması, kısa sürede tamamlanması, tüm vücudun değerlendirilmesine olanak sağlaması, bütün işyerlerinde kullanılabilir olması, detaylı ve duyarlı bir yöntem olması diğer postür analiz metotlarına göre temel avantajlarıdır (Hignett ve ark, 2000). Biz de çalışmamızda öğretmenlerin çalışma postürünü HTVD yöntemi ile değerlendirdik. Çalışmamızda bel ağrısı olan öğretmenlerde bel ağrısı olmayanlara göre HTVD skorunun anlamlı olarak daha yüksek olduğu ve çalışma postürünün daha olumsuz etkilendiği bulundu. Çalışmamızda HTVD skoruna göre bel ağrısı olan grupta genel kas iskelet sistemi problemleri gelişme düzeyi orta ve yüksek iken, bel ağrısı olmayan öğretmenlerde genel kas iskelet sistemi problemleri gelişme düzeyi düşük ve orta düzeyde olduğu bulundu. HTVD skoru sonuçlarına göre, bel ağrısı olmayan öğretmenlere kas iskelet problemlerini önlemek için fiziksel aktivite önerilebileceği, bel ağrısı olan öğretmenlere de fiziksel aktivite/egzersiz önerilmesi gerektiği öngörülmektedir. Öğretmenlere uygun fiziksel aktivite/egzersiz ve ergonomik farkındalık eğitimlerinin verilmesi bu meslek grubunda kas iskelet sistemi problemlerinin önlenmesinde önemli olabilir.

Çalışma koşulları birçok meslekte olduğu gibi öğretmenlerde de bel ağrısının gelişmesinde önemli olabilmektedir. Öğretmenlerde yapılan birçok çalışmada (Cardosa ve ark, 2009; Edling ve Fjellman-Wiklund, 2009; Bandpeive Ftemeh, 2014) mesleki deneyim yılı arttıkça bel ağrısı riskinin arttığı bildirilse de,Yue ve arkadaşlarının çalışmasında (Yue, Fengling ve Liping, 2012) mesleki deneyim yılı ile bel ağrısı varlığı arasında bir ilişki saptanamamıştır. Biz de çalışmamızda mesleki deneyim yılı açısından gruplar arasında anlamlı bir farklılık bulmadık.Bu durum öğretmenlerin branş, okul seviyesi açısından heterojen dağılımından kaynaklanabilir. Literatürde uzun süreli oturma ve uzun süreli ayakta durma ile bel ağrısı varlığı ilişkisi net olarak ortaya konamamıştır. Bazı çalışmalarda bilgisayar başında geçirilen süre arttıkça kas iskelet sistemi rahatsızı̆̆ı riskinin arttığı bildirilmiştir (Çalık,
Atalay ve Başkan, 2013; Gerr, 2002).Çalışmamızda da, bel ağrısı olan ve olmayan öğretmenlerde oturma, ayakta durma ve bilgisayar başında geçirilen sürelerin benzer olduğu görüldü. $\mathrm{Bu}$ sonuçlar öğretmenlerin farklı branşlara sahip olmaları ve çalışma metodundaki farklılıklar nedeniyle olabilir. Cardosa ve arkadaşlarının çalışmasında (Cardosa ve ark, 2009) öğretmenlerde danışmanı olunan öğrenci sayısı ile bel ağrısı görülme sıklığı arasında anlamlı bir ilişki bulunmamıştır. Benzer olarak biz de çalışmamızda dersine girilen ve not verilen öğrenci sayısı sorgulanmış olup bel ağrısı olan ve olmayan öğretmenlerde danışmanı olunan öğrenci sayısı benzer bulundu. Çalışmamız, bel ağrısı olan grupta tam zamanlı çalışma şeklinin daha fazla olduğu gösterilmiş olup, günlük uzun süreli çalışmanın öğretmenlerde bel ağrısı görülme sıklığını artırdığını gösteren çalışmaları (Yue ve ark, 2012) desteklemektedir. Bandpei ve arkadaşları (Bandpei ve ark, 2014) ile Yue ve arkadaşlarının (Yue ve ark, 2012) yaptığı iki farklı çalışmada, çalışmamıza benzer şekilde lise seviyesinde çalışanlarda bel ağrısı görülme riski ortaokul ve ilkokul öğretmenlerine kıyasla anlamlı olarak daha fazla bulunmuştur. Ülkemizdeki çalışma temposunun lise öğretmenlerinde daha yoğun olması, özellikle üniversite sınavına hazırlık süreci lisede çalışan öğretmenlerin bel ağrısının daha çok görülmesinde önemli olabilir.

Öğretmenlerde bel ağrısı varlığı iş veriminin azalması, fiziksel aktivitenin kısıtlanmasına, psikolojik durumun kötüleşmesine ve bu nedenlerin etkisi ile de yaşam kalitesinin olumsuz etkilenmesine neden olabilmektedir (Tsuboi, Tkeuchi ve Watanabe, 2012). Literatürde Durmuş ve arakadaşları (Durmus ve ark, 2012) ile Karakaya ve arkadaşlarının (Karakaya ve ark, 2015) yaptığı iki farklı çalışmada KF-36 alt parametrelerinin bel ağrısı olan öğretmenlerde farklı oranlarda olumsuz yönde etkilendiği bildirilmiştir. Çalışmamızda da yaşam kalitesi ile ilgili zihinsel sağlık parametresi dışındaki fiziksel fonksiyon, fiziksel rol kısıtlılığı, duyusal rol kısıtlılığı, enerji, sosyal fonksiyon, bedensel ağrı ve genel sağlık algısı parametreleri bel ağrısı olan öğretmenlerde anlamlı olarak daha düşük bulundu. $\mathrm{Bu}$ durum bel ağrısının yaşam kalitesinde belirgin kötüleşmeye neden olduğunu göstermektedir. Ancak, yaşam kalitesinin zihinsel sağlık parametresinin iki grup arasında benzer olması öğretmenlerinin çalıştığı okul ve branştaki sosyal ortamın varlığından ve mesleği gereği sürekli yeni bilgiler elde edinmesinden kaynaklanmış olabilir. 
Çalışmamızda bazı limitasyonlar bulunmaktadır. Çalışmamızda öğretmenlerin çalışma postürü HTVD ile öğretmenlerin en çok kullandıkları 4 pozisyonda fotoğraf çekimi yapılarak değerlendirildi. Sürenin kısıtı olması öğretmenlerin çalışmaya katılımını artırmak amacı ile HTVD yöntemi fotoğraf çekimi ile yapıldı. Ancak ileriki çalışmalarda sınıf ortamına yerleştirilen bir kamera yardımıyla sık tekrarlanan, uygun olmayan vücut postürleri belirlenerek video analiz yöntemi ile çalışma postürlerinin daha ayrıntıı değerlendirilmesi yapılabilir.

Sonuç olarak çalışmamızda, bel ağrısı olan öğretmenlerin bel ağrısı olmayan öğretmenlere çalışma postürünün daha kötü olduğu, lisede çalışan öğretmen sayısı ve tam zamanlı olarak çalışma şeklinin daha fazla olduğu ve yaşam kalitelerinin olumsuz yönde etkilendiği saptandı. Bel ağrısı için riskli bir grup olan öğretmenlere çalışma postürü ile ilgili eğitimler, ergonomik prensipler ile ilgili bilgiler ve iş ortamında yapabilecekleri egzersiz önerileri verilerek öğretmenlerin bel ağrısı ve gelişme riski azaltılabilir ve iş verimleri artırılabilir.

\section{Kaynaklar}

Apaydin, U., Erol, E., \&Kocyigit, M.F. (2016). Determination of the factors correlated with low back pain in teachers. Turk J Physiother Rehabil, 27,42-47.

Atasoy, A. (2010). Occupational musculoskeletal system troubles and assessment of ergonomic risks in laboratory staff. Sağlıkta Performans ve Kalite Dergisi,2(2),90-113.

Ayanoğlu, C. (2007). İşyerinde ergonomi ve stres. Isş Sağlığı ve Güvenliği Dergisi, 34.

Balagué, F.,Mannion, A.F., \&Pellisé, F. (2012). Non-specific low back pain. Lancet, 379, 482-91.

Bandpei, M.,\&Fatemeh, E. (2014). Occupational low back pain in primary and high school teachers: prevalence and associated factors. J Manipulative Physiol Ther,37,702708.

Bednar, D.A.,Orr, F.W., \&Simon, G.T. (1995). Observations on the pathomorphology of the thoracolumbar fascia in chronic mechanical back pain. A microscopic study. Spine, 20(10), 1161-1164.

Bilir, N. (2007). Mesleksel kas iskelet sistemi hastalıkları. Iş Sağlığı ve Güvenliği Dergisi, 34,10-13.

Cardoso, J.P., De Queiroz Batista Ribeiro, I., \& Maria de Araújo, T. (2009). Prevalence of musculoskeletal pain among teachers. Revista Brasileira de Epidemiologia, 12(4), 1-10.

Chiasson, M.,Imbeau, D., \&Aubry, K. (2012). Comparing the results of eight methods used to evaluate risk factors associated with musculoskeletal disorders. Int $J$ Indust Ergonom, 42,478-488.

Clark, P.,Lavielle, P., \&Martínez, H. (2003). Learning frompainscales: patient perspective. Rheumatol,30,1584-1588.

Çalık, B.B., Atalay, O.T., \& Başkan, E. (2013). Bilgisayar kullanan masa başı çalışanlarında kas iskelet sistemi rahatsızlıkları, işin engellenmesi ve risk faktörlerinin incelenmesi. Clin Exp Health Sci,3(4),208-214.

David, G.C. (2005). Ergonomic methods for assessing exposure to risk factors for work-related musculoskeleta disorders. Occup Med (Lond), 55(3),190-199.
De Sa, F.,\&Nascimento, M.D. (2006). Comparison of methods RULA and REBA for evaluation of postural stress in odontological services. Proceedings of the $3 \mathrm{rd}$ Conference on ProductionResearch-Americas' Region (ICPR-AM' 06).

Dima, A.M.,\&Awwad, D. (2016). Rapid Entire Body Assessment: A Literature Review. Am J EngAppl Sci,9(1),107-118.

Durmus, D.,\&llhanlı, İ. (2012). Are there work-related musculoskeletal problems among teachers in Samsun, Turkey?.J Back Musculoskelet Rehabil, 25(1),5-12.

Edling, C.W.,\&Fjellman-Wiklund, A. (2009). Musculoskeletal disorders and asymmetric playing postures of the upper extremity and back in music teachers: a pilot study. Med Probl Perform Art, 24(3),113-118.

Gentzler, M.,\&Stader, S. (2010). Posture stress on fire fighters and Emergency Medical Technicians (EMTs) associated with repetitive reaching, bending lifting and pulling tasks. Work,37,227-239.

Gerr, F. (2002). A prospective study of computer users: I. Study design and incidence of musculoskeletal symptoms and disorders. Am J Ind Med, 41(4),221-235.

Hashim, A.M.,Dawal, S.Z., \&Yusoff, N. (2012). Ergonomic evaluation of postural stress in school workshop. Work, 41,827-831.

Hignett, S.,\&McAtamney, L. (2000). Rapid entire body assessment (REBA). Appl Ergon, 31(2),201-205.

Hoy, D.,Brooks, P., \&Blyth, F. (2010). The Epidemiology of low back pain. Best Pract Res Clin Rheumatol,24(6),769-781.

Janowitz, I.,Gillen, M., \&Ryan, G. (2006). Measuring the physical demands of work in hospital settings: Design an dimplementation of an ergonomics assessment. Applied Ergonom, 37,641-658.

Jiménez-Sánchez, S.,Fernández-de-las-Peñas, C., \&Carrasco-Garrido, P. (2012). Prevalence of chronic head, neck and low back pain and associated factors in women residing in the autonomous region of Madrid (Spain). Gac Sanit, 26, 534-540.

Jones, T.,\&Kumar, S. (2010). Comparison of ergonomic risk assessment output in four saw milljobs. Int J Occupat Safety Ergonom,16,105-111.

Joseph, C.,\&Imbeau, D. (2011). Measurement consistency among observational job analysis methods during an intervention study. Int J Occupat Safety Ergonom, 17,139146.

Karakaya, I.C., Karakaya, M.G., \&Tunc, E. (2015). Musculoskeletal problems and quality of life of elementary school teachers. Int J Occup Saf Ergon, 21(3),344-350.

Katz, N. (2002). The impact of pain management on quality of life. J Pain Symptom Manag, 24(1),38-47.

Kee, D.,\&Karwowski, W. (2007). A comparison of three observational techniques for assessing postural loads in industry. Int J Occupat Safety Ergonom,13,3-14.

Klineberg, E.,Mazanec, D., \&Orr, D. (2007). Masquerade: medicalcauses of back pain. Cleve Clin J Med,74,905913.

Krismer, M.,\& Van Tulder, M.W. (2007). Low back pain (nonspecific). Best Pract Res Clin Rheumatol, 21,77-91.

Kocyigit, H., Aydemir, O., \&Fisek, G. (1999). Reliability and validity of the Turkish version of Short-Form-36 (SF-36). İlaç ve Tedavi Dergisi,12,102-106.

Langevin, H.M.,\&Sherman, K.J. (2007). Pathophysiological model for chronic low back pain integrating connective tissue and nervous system mechanisms. Med Hypotheses, 68(1), 74-80.

Pillastrini, P. (2007). Evaluation of two preventive interventions for reducing musculoskeletal complaints in operators of video display terminals. Phys Therapy, 87,536-544.

Shanahan, C.,Vi, P., \&Salas, E. (2013). A comparison of RULA, REBA and Strain Index to four psychophysical scales in the assessment of non-fixed work. Work, 45,367-378. 
Stanton, N. (2005). Handbook of Human Factorsand Ergonomics Methods. Boca Raton: CRC Press.

Tsuboi, H.,Tkeuchi, K., Watanabe, M., Hori, R., \&Kobayashi, F. (2002). Psychosocial factors related to low back pain among school personel in Nagoya. Ind Health,40(3),266271.

Valkenburg, H.A.,\&Haanen, H.C.M. (1982). The epidemiology of low back pain. In: Symposium on Idiopathic Low Back Pain,Mosby, 1982,9-22.

Van Tulder, M.W.,Koes, B.W., \&Bombardier, C. (2002). Low back pain. Best Pract Res Clin Rheumatol Int,16,761-775.

Yue, P.,Fengling, L., \&Liping, L. (2012). Neck/shoulder pain and low back pain among school teachers in China, prevalenceand risk factors. BMC Public Health, 12,789. 